Supporting Information for

\title{
Bay-Substitution Effect of Perylene Diimides on Supramolecular Chirality and Optoelectronic Properties of Their Self-Assembled Nanostructures
}

Xiaobo Shang,,$^{\dagger, \Delta, \perp}$ Jaeyong Ahn, ${ }^{\dagger, \perp}$ Jeong Hyeon Lee, ${ }^{\S}$ Jin Chul Kim, ${ }^{\S}$ Hiroyoshi Ohtsu, Wanuk Choi, ${ }^{\#}$ Inho Song, ${ }^{\dagger}$ Sang Kyu Kwak, ${ }^{\S}$ and Joon Hak Oh*,†

${ }^{\dagger}$ School of Chemical and Biological Engineering, Institute of Chemical Processes, Seoul National University, 1 Gwanak-ro, Gwanak-gu, Seoul 08826, Republic of Korea

${ }^{\Delta}$ State Key Laboratory for Mechanical Behavior of Materials, Shaanxi International Research Center for Soft Matter, School of Materials Science and Engineering, Xi'an Jiaotong University, Xi'an 710049, P. R. China

${ }^{\S}$ Department of Energy Engineering, School of Energy and Chemical Engineering, Ulsan National Institute of Science and Technology (UNIST), Ulsan 44919, Republic of Korea

Department of Chemistry, School of Science, Tokyo Institute of Technology, 2-12-1 Ookayama, Meguro-ku, Tokyo 152-8550, Japan

\#Energy Materials Laboratory, Korea Institute of Energy Research (KIER), Daejeon, 34129, Republic of Korea

*E-mail: joonhoh@snu.ac.kr 


\section{Supporting Figures}

HOMO and LUMO electron distributions of bay-substituted PDI materials (Figure S1) ------------------- S3

Cyclic voltammetric results of bay-substituted PDI materials (Figure S2) ------------------------------- S4

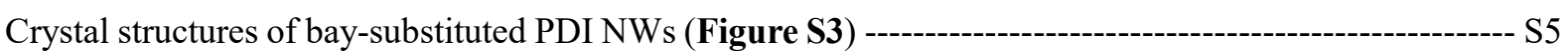

Optical microscope images of bay-substituted PDI NWs (Figure S4) --------------------------------- S6

Output characteristics of bay-substituted PDI NWs-based OFETs (Figure S5) -------------------------- S7

Electrostatic potential-mapped electron density of bay-substituted PDI molecules (Figure S6) ------------- S8

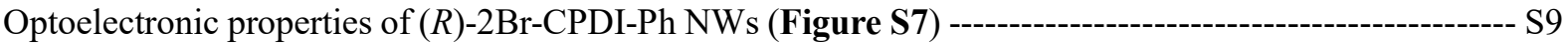

Optoelectronic properties of $(R)$-2F-CPDI-Ph NWs (Figure S8) ----------------------------------------- S10

\section{Supporting Tables}

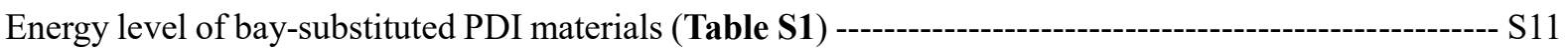

Electrical characteristics of bay-substituted PDI NWs-based OFETs (Table S2) --------------------------- S11

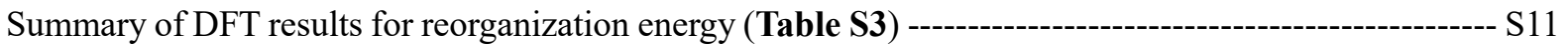

Structural information of pairs in DFT-optimized bay-substituted PDIs (Table S4) --------------------- S12

Optoelectronic characteristics of bay-substituted PDI NWs-based OPTs (Table S5) ----------------------- S12

\section{Supporting Contents}

I. Experimental Methods

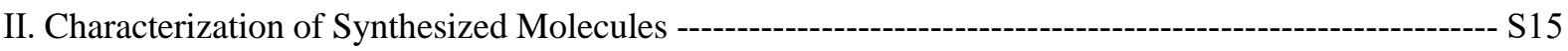

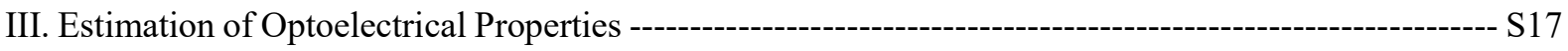

IV. X-ray Crystallography ----_--- S19 
(a)

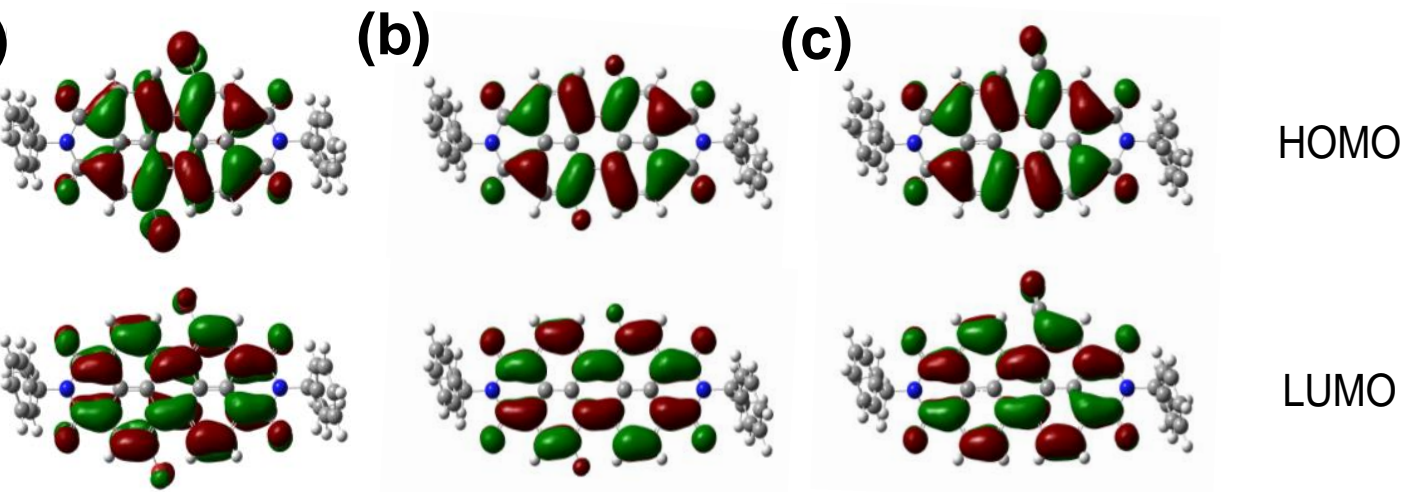

Figure S1. HOMO and LUMO electron distributions of (a) $(R)-2 \mathrm{Br}-\mathrm{CPDI}-\mathrm{Ph},(\mathrm{b})(R)-2 \mathrm{~F}-$ CPDI-Ph, and (c) (R)-CN-CPDI-Ph obtained by DFT calculations. 
(a)

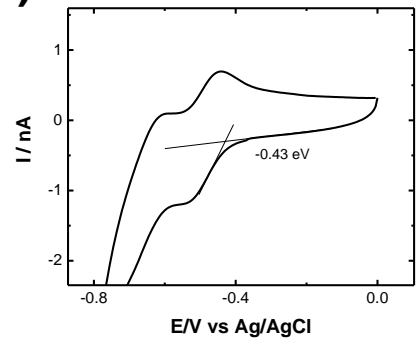

(b)

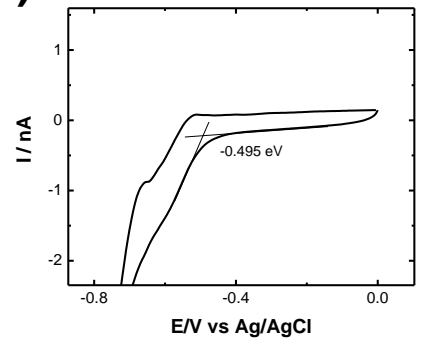

(c)

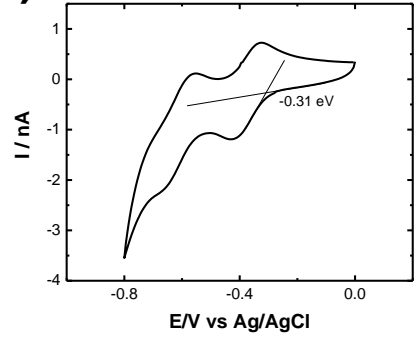

Figure S2. Cyclic voltammetry results of (a) (R)-2Br-CPDI-Ph, (b) $(R)-2 \mathrm{~F}-\mathrm{CPDI}-\mathrm{Ph}$, and (c) $(R)$-CN-CPDI-Ph in chloroform solutions $\left(10^{-4} \mathrm{M}\right)$. 
(a)

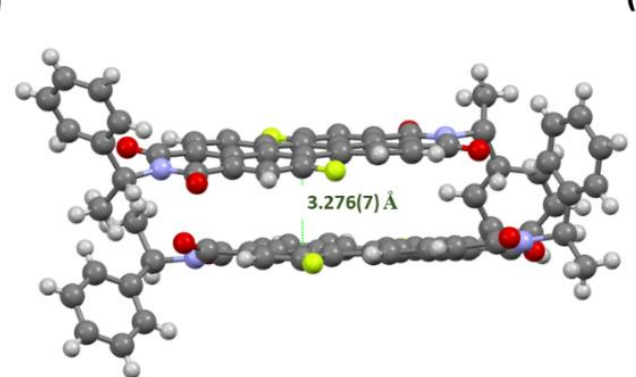

(c)

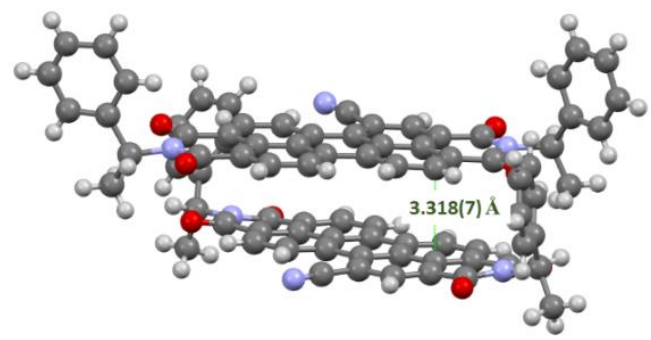

(b)

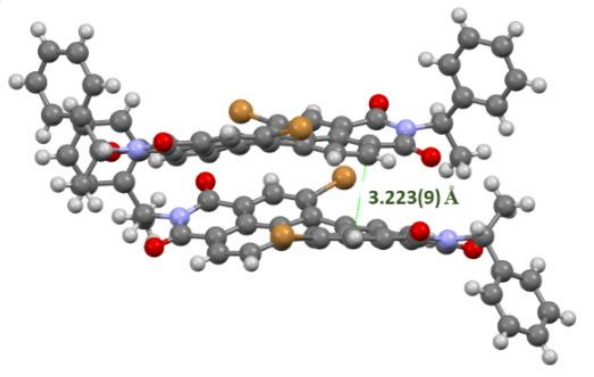

Figure S3. Crystal structures showing shortest C...C distances for $\pi-\pi$ stacking of (a) (R)-2FCPDI-Ph, (b) (R)-2Br-CPDI-Ph, (c) (R)-CN-CPDI-Ph. Color code: C, gray; N, blue; O, red; F, green; $\mathrm{Br}$, brown; $\mathrm{H}$, white. 
(a)

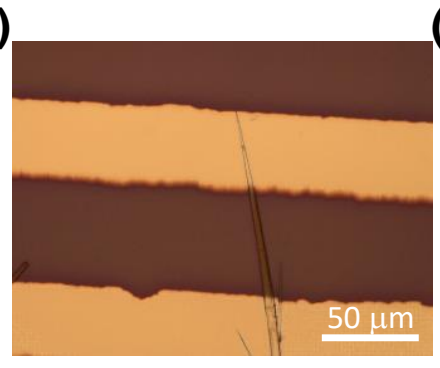

(b)

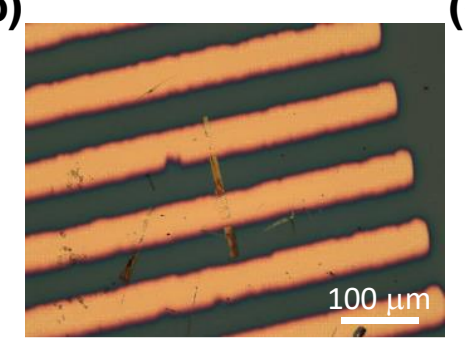

(c)

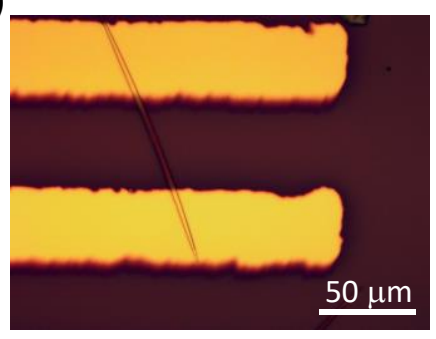

Figure S4. Optical microscope images of (a) (R)-2Br-CPDI-Ph, (b) $(R)-2 \mathrm{~F}-\mathrm{CPDI}-\mathrm{Ph}$, and (c) $(R)$-CN-CPDI-Ph NWs. 
(a)

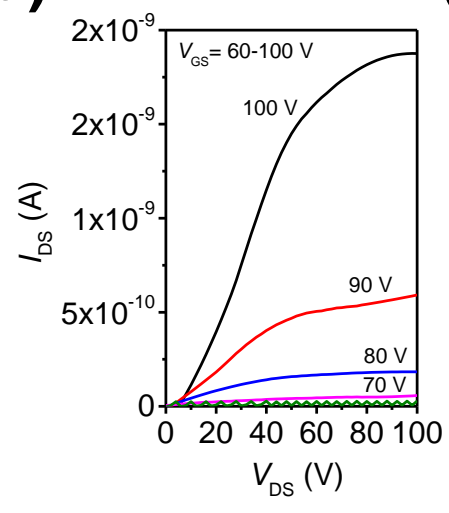

(b)

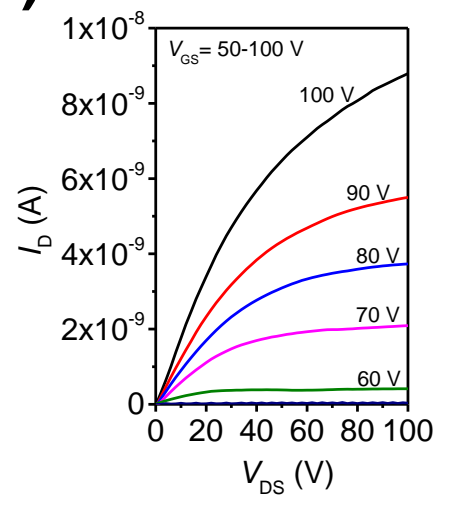

(c)

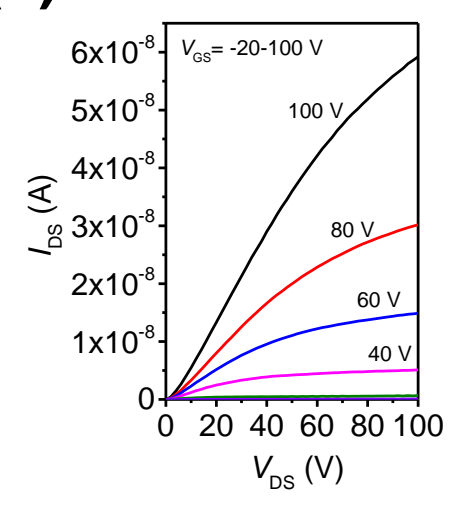

Figure S5. Output characteristics of (a) (R)-2Br-CPDI-Ph, (b) $(R)-2 \mathrm{~F}-\mathrm{CPDI}-\mathrm{Ph},(\mathrm{c})(R)-\mathrm{CN}-$ CPDI-Ph NWs-based OFET in the dark condition. 
(R)-2Br-CPDI-Ph

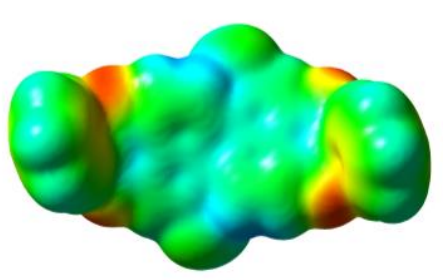

(R)-2F-CPDI-Ph

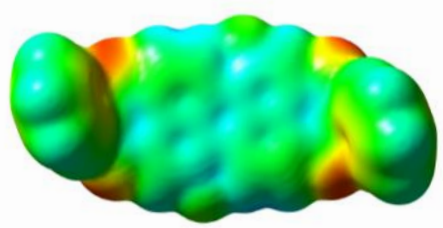

(R)-CN-CPDI-Ph

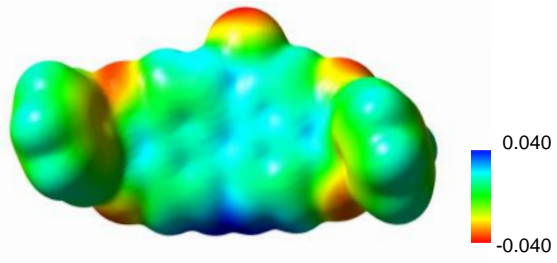

Figure S6. Electrostatic potential-mapped electron density of bay-substituted PDI molecules. Red and blue represent the electron rich and deficient regions, respectively. 
(a)

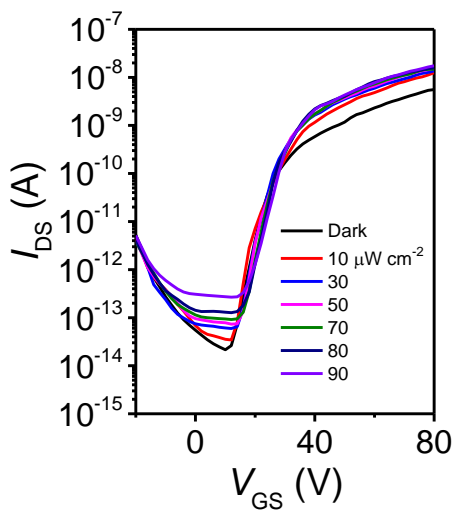

(b)

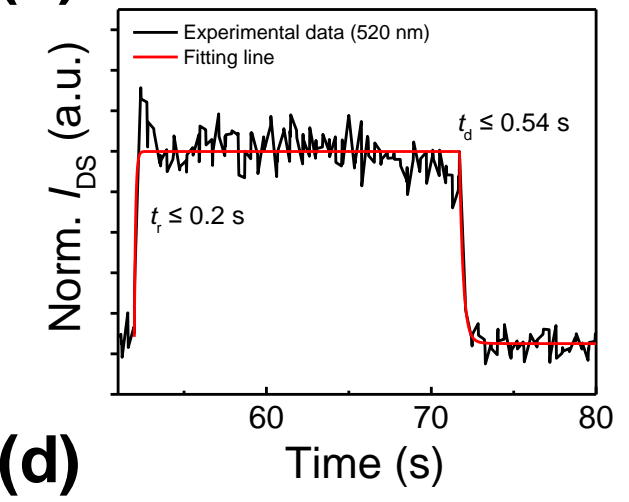

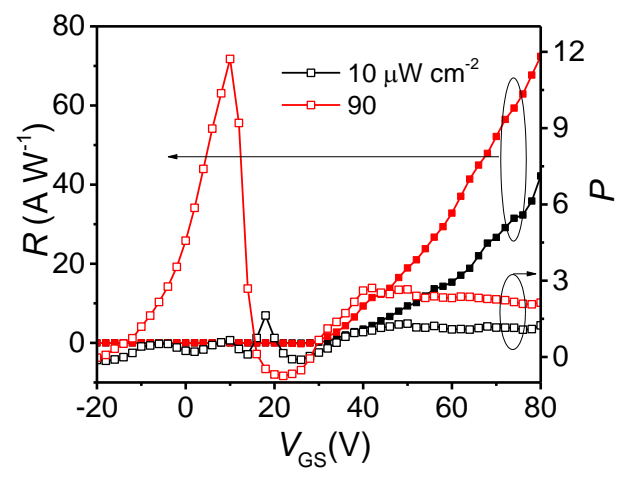

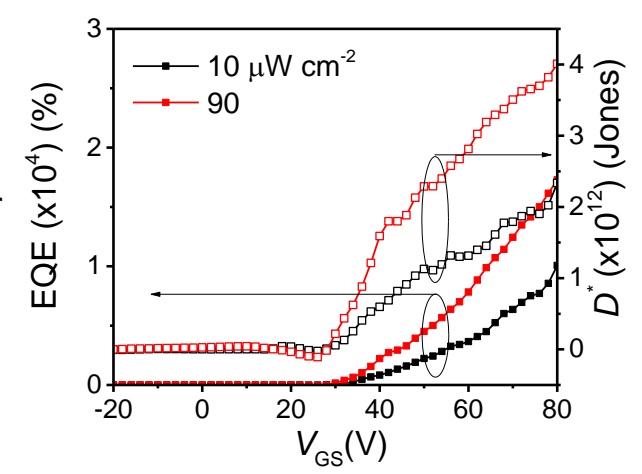

Figure S7. (a) $I_{\mathrm{DS}}-V_{\mathrm{GS}}$ characteristics of $(R)-2 \mathrm{Br}-\mathrm{CPDI}-\mathrm{Ph} \mathrm{NWs}$ in the dark and under monochromatic light illumination $(\lambda=520 \mathrm{~nm})$ with various intensities. (b) Bi-exponential fitting result for the photoresponse time calculation, (c) Photoresponsivity, photosensitivity, (d) EQE, and specific detectivity of (R)-2Br-CPDI-Ph NW-based OPTs under 10 and $90 \mu \mathrm{W} \mathrm{cm}{ }^{-2}$ light intensities. 
(a)

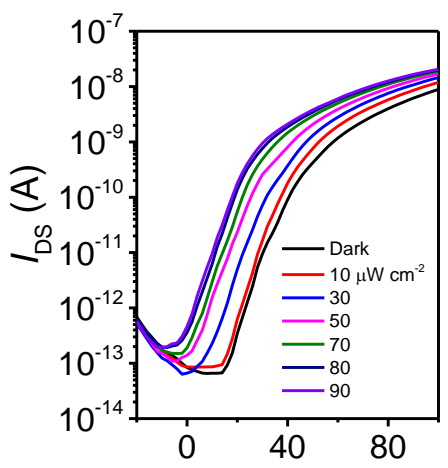

(c)

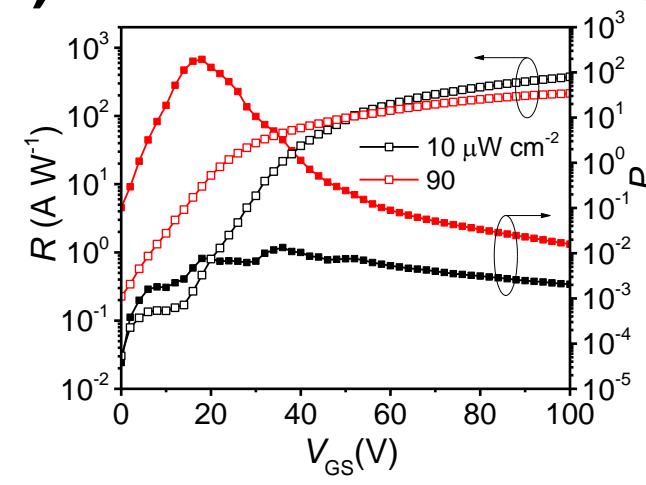

(b)

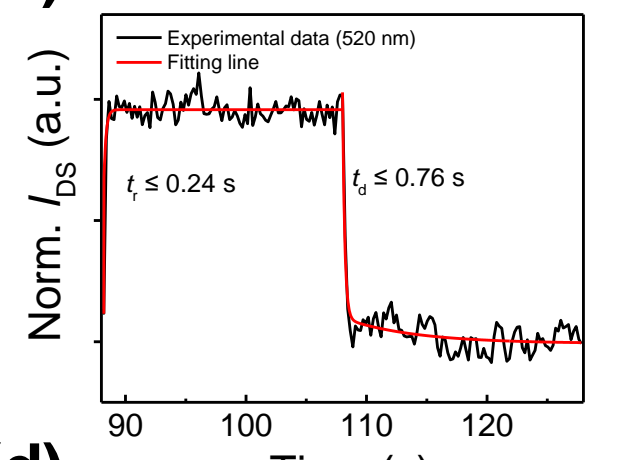

(d)

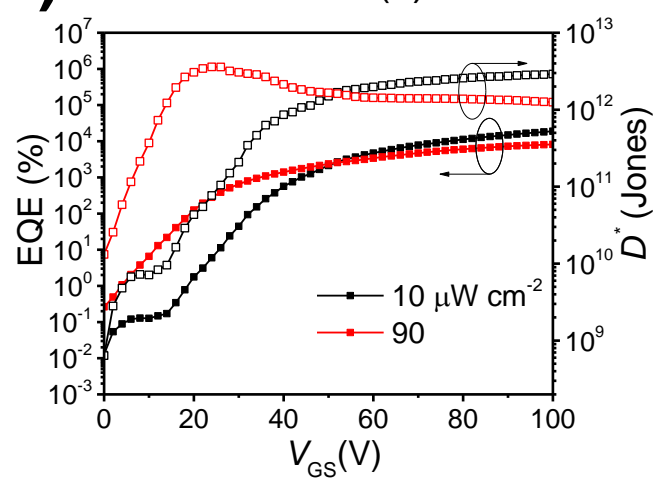

Figure S8. (a) $I_{\mathrm{DS}}-V_{\mathrm{GS}}$ characteristics of $(R)-2 \mathrm{~F}-\mathrm{CPDI}-\mathrm{Ph}$ NWs in the dark and under monochromatic light illumination $(\lambda=520 \mathrm{~nm})$ with various intensities. (b) Bi-exponential fitting result for the photoresponse time calculation. (c) Photoresponsivity, photosensitivity, (d) EQE, and specific detectivity of (R)-2F-CPDI-Ph NW-based OPTs under 10 and $90 \mu \mathrm{W} \mathrm{cm}{ }^{-2}$ light intensities. 
Table S1. Energy level of bay-substituted PDI materials from CV measurements and DFT calculations.

\begin{tabular}{|c|c|c|c|}
\hline & Material & Orbital & Energy level (eV) \\
\hline \multirow{6}{*}{ DFT } & \multirow{2}{*}{$(R)-2 \mathrm{Br}-\mathrm{CPDI}-\mathrm{Ph}$} & LUMO & -3.90 \\
\hline & & HOMO & -6.40 \\
\hline & \multirow{2}{*}{$(R)-2 \mathrm{~F}-\mathrm{CPDI}-\mathrm{Ph}$} & LUMO & -3.84 \\
\hline & & HOMO & -6.37 \\
\hline & \multirow{2}{*}{$(R)-\mathrm{CN}-\mathrm{CPDI}-\mathrm{Ph}$} & LUMO & -4.07 \\
\hline & & HOMO & -6.54 \\
\hline \multirow{6}{*}{$\mathrm{CV}$} & \multirow{2}{*}{$(R)-2 \mathrm{Br}-\mathrm{CPDI}-\mathrm{Ph}$} & LUMO & -3.87 \\
\hline & & HOMO & -6.12 \\
\hline & \multirow{2}{*}{$(R)-2 \mathrm{~F}-\mathrm{CPDI}-\mathrm{Ph}$} & LUMO & -3.81 \\
\hline & & HOMO & -6.17 \\
\hline & \multirow{2}{*}{$(R)-\mathrm{CN}-\mathrm{CPDI}-\mathrm{Ph}$} & LUMO & -3.99 \\
\hline & & HOMO & -6.25 \\
\hline
\end{tabular}

Table S2. Electrical characteristics of bay-substituted PDI NWs-based OFETs

\begin{tabular}{cccc}
\hline Material & $\mathrm{I}_{\mathrm{on}} / \mathrm{I}_{\mathrm{off}}$ & $V_{\mathrm{T}}(\mathrm{V})$ & $\mu^{\mathrm{a}}\left(\mathrm{cm}^{2} \mathrm{~V}^{-1} \mathrm{~s}^{-1}\right)$ \\
\hline$(R)-2 \mathrm{Br}-\mathrm{CPDI}-\mathrm{Ph}$ & $>10^{3}$ & $24.1( \pm 10.4)$ & $0.019( \pm 0.021)$ \\
$(R)-2 \mathrm{~F}-\mathrm{CPDI}-\mathrm{Ph}$ & $>10^{3}$ & $28.1( \pm 11.3)$ & $0.038( \pm 0.026)$ \\
$(R)-\mathrm{CN}-\mathrm{CPDI}-\mathrm{Ph}$ & $>10^{3}$ & $-1.00( \pm 8.78)$ & $0.074( \pm 0.031)$ \\
\hline
\end{tabular}

${ }^{a}$ Average values extracted from more than ten NWs.

Table S3. Summary of DFT results for the calculation of electron reorganization energy and electron affinity.

\begin{tabular}{ccccccccc}
\hline & $\begin{array}{c}\boldsymbol{E}_{\mathbf{0}} \\
\mathbf{H a})\end{array}$ & $\begin{array}{c}\boldsymbol{E}_{\mathbf{0}}^{*} \\
\mathbf{H a})\end{array}$ & $\begin{array}{c}\boldsymbol{E}_{-} \\
\mathbf{( H a )}\end{array}$ & $\begin{array}{c}\boldsymbol{E}_{-}^{*} \\
\mathbf{( H a )}\end{array}$ & $\begin{array}{c}\boldsymbol{\lambda}_{\mathbf{0}} \\
(\mathbf{m e V})\end{array}$ & $\begin{array}{c}\boldsymbol{\lambda}_{-} \\
(\mathbf{m e V})\end{array}$ & $\begin{array}{c}\boldsymbol{\lambda} \\
(\mathbf{m e V})\end{array}$ & $\begin{array}{c}\mathbf{E A} \\
(\mathbf{e V})\end{array}$ \\
\hline $\mathbf{2 B r}$ & -7092.796 & -7092.791 & -7092.904 & -7092.898 & 148.3 & 149.7 & 298.0 & 2.92 \\
$\mathbf{2 F}$ & -2149.035 & -2149.029 & -2149.139 & -2149.133 & 148.6 & 151.3 & 299.9 & 2.83 \\
$\mathbf{C N}$ & -2042.798 & -2042.793 & -2042.910 & -2042.905 & 137.2 & 138.6 & 275.8 & 3.34 \\
\hline
\end{tabular}


Table S4. Structural information of pairs in DFT-optimized bay-substituted PDI crystals. Center of PDI was defined as center of mass of the central benzene ring. Stacking distance was defined as the distance from one center to the other PDI plane.

\begin{tabular}{ccccc}
\hline & & $\begin{array}{c}\text { Center-to-center } \\
\text { distance }(\AA)\end{array}$ & $\begin{array}{c}\text { Stacking distance } \\
(\AA)\end{array}$ & $\begin{array}{c}\text { Angle between } \\
\text { PDI planes }\left(^{\circ}\right)\end{array}$ \\
\hline & $l_{1}$ & 4.47 & 3.36 & 9.60 \\
$(R)-2 B r-C P D I-P h$ & $l_{2}$ & 4.38 & 3.52 & 9.60 \\
& $l_{3}$ & 19.02 & 0.26 & 9.60 \\
& $l_{4}$ & 10.33 & 2.85 & 6.62 \\
\hline & $l_{1}$ & 3.95 & 3.59 & 8.87 \\
$(R)-2$ F-CPDI-Ph & $l_{2}$ & 4.41 & 3.33 & 8.87 \\
& $l_{3}$ & 12.22 & 0.88 & 0.0 \\
& $l_{4}$ & 15.76 & 3.19 & 8.87 \\
\hline \multirow{4}{*}{$(R)-\mathrm{CN}-\mathrm{CPDI}-\mathrm{Ph}$} & $l_{1}$ & 4.58 & 3.32 & 3.28 \\
& $l_{2}$ & 3.57 & 3.42 & 3.28 \\
& $l_{3}$ & 10.67 & 4.67 & 32.01 \\
& $l_{4}$ & 11.11 & 4.35 & 34.67 \\
\hline
\end{tabular}

Table S5. Optoelectronic characteristics of bay-substituted PDI NWs-based OPTs.

\begin{tabular}{ccccc}
\hline Material & $P^{\mathrm{a}}$ & $R\left(\mathrm{~A} \mathrm{\textrm {W } ^ { - 1 }}\right)$ & $\mathrm{EQE}(\%)$ & $D^{*}(\mathrm{Jones})$ \\
\hline$(R)-2 \mathrm{Br}-\mathrm{CPDI}-\mathrm{Ph}$ & 2.0 & 49 & 11749 & $2.7 \times 10^{12}$ \\
$(R)-2 \mathrm{~F}-\mathrm{CPDI}-\mathrm{Ph}$ & 16 & 50 & 11955 & $1.8 \times 10^{12}$ \\
$(R)-\mathrm{CN}-\mathrm{CPDI}-\mathrm{Ph}$ & 51 & 209 & 49680 & $4.1 \times 10^{12}$ \\
\hline
\end{tabular}

${ }^{\mathrm{a}}$ Maximum values under monochromic light illumination $\left(\lambda=520 \mathrm{~nm}, 30 \mu \mathrm{W} \mathrm{cm}^{-2}\right)$ 


\section{Experimental Methods}

Synthesis of chiral semiconductors and self-assembly for NWs:<smiles>O=C1OC(=O)c2ccc3c4c(Br)cc5c6c(ccc(c7ccc1c2c73)c64)C(=O)OC5=O</smiles><smiles>CC(N)c1ccccc1</smiles><smiles>C[C@H](N=O)c1ccccc1</smiles>

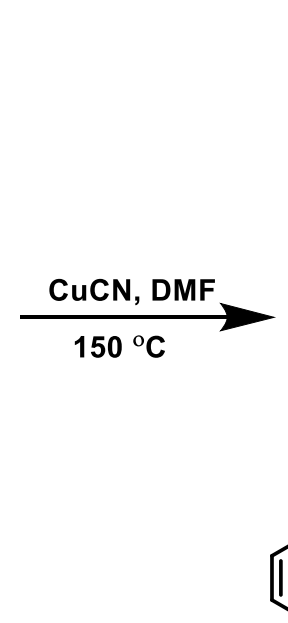

(R)-Br-CPDI-Ph<smiles>C[C@H](c1ccccc1)N1C(=O)c2ccc3c4ccc5c6c(cc(C#N)c(c7ccc(c2c37)C1=O)c64)C(=O)N([C@H](C)c1ccccc1)C5=O</smiles>

$(R)-C N-C P D I-P h$

Figure S9. Synthesis scheme of $(R)-\mathrm{CN}-\mathrm{CPDI}-\mathrm{Ph}$.

$(R)$-Br-CPDI-Ph: a mixture of Br-PTCDA (1.82 mol), $(R)$-1-phenylethylamine $(1 \mathrm{~mL})$ and zinc acetate $(10 \mathrm{mg})$ in quinolone $(12 \mathrm{~mL})$ for $3 \mathrm{~h}$ at $130^{\circ} \mathrm{C}$. After cooling to room temperature, the mixture was poured into $2 \mathrm{~N} \mathrm{HCl}(200 \mathrm{~mL})$ and the precipitate was filtered and dried in vacuum. The product was obtained after column chromatography using dichloromethane as the eluent with the yield of $35 \%$.

(R)-CN-CPDI-Ph: $(R)$-Br-CPDI-Ph $(0.57 \mathrm{mmol})$ and $\mathrm{CuCN}(5.1 \mathrm{mmol})$ were added to a 100 $\mathrm{mL}$ three-necked flask. Then DMF $(22 \mathrm{~mL})$ was added and the mixture was heated to $150{ }^{\circ} \mathrm{C}$ under nitrogen overnight. After cooling down to room temperature, the mixture was poured into water $(35 \mathrm{~mL})$. The precipitate was recovered by filtration, dried under a nitrogen stream, and the crude product was purified by column chromatography with the yield of $75 \%$.

Materials analysis: The ${ }^{1} \mathrm{H}$ NMR and ${ }^{13} \mathrm{C}$ NMR spectra were measured on a Bruker Avance III (Ultrashield Plus $400 \mathrm{MHz}$ magnet) spectrometer using tetramethylsilane as the internal standard. SEM images were observed using a MERLIN Compact field emission scanning electron microscope. The optical images in this study were obtained using Olympus BX53F 
model. The absorption spectra were measured using a Cary 5000 UV-vis-NIR spectrophotometer. The CD results were obtained using a $J-815$ Spectropolarimeter (JASCO). We used chloroform as the solvent to measure the absorption and CD spectra at a concentration of $10^{-5} \mathrm{M}$. In the case of NWs, samples were prepared on the quartz plate by drop-cast method using filtered NWs dispersed in ethanol. The solution was repeatedly dropped to cover sufficient part of the quartz surface with NWs.

Cyclic voltammetric measurements: Cyclic voltammetric measurements were performed using a three-electrode cell with a polished $2 \mathrm{~mm}$ glassy carbon as working electrode, $\mathrm{Pt}$ as counter electrode, and $\mathrm{Ag} / \mathrm{AgNO}_{3}$ as reference electrode; solutions in chloroform were $1 \times 10$ ${ }^{4} \mathrm{M}$ for PDIs and $0.10 \mathrm{M}$ for supporting electrolyte, tetrabutylammonium hexafluorophosphate $\left(\mathrm{TBAPF}_{6}\right)$. In order to calculate the LUMO levels with respect to the vacuum level, the redox data were standardized to the ferrocene/ferrocenium couple having a calculated absolute energy of $-4.8 \mathrm{eV}$, using the following equation (S1). The HOMO levels were calculated using the optical band gap of UV-vis spectra.

$$
E_{\text {LUMO }}=-\left(\left(E_{\text {onset }, \text { red }}-E_{1 / 2(\text { Ferrocene })}\right)+4.8\right)[\mathrm{eV}]
$$

Analysis of Crystal Structures: The single crystal X-ray diffraction data of (R)-2Br-CPDI$\mathrm{Ph},(R)-2 \mathrm{~F}-\mathrm{CPDI}-\mathrm{Ph}$ and $(R)-\mathrm{CN}-\mathrm{CPDI}-\mathrm{Ph}$ were collected in beamline 2D of Pohang Accelerator Laboratory (PAL) with an MX225-HS CCD area detector using synchrotron radiation $(\lambda=0.7000 \AA)$ and on a Bruker APEX II QUAZAR instrument in house with Mo K $\alpha$ source $(\lambda=0.71073 \AA)$, respectively. All the structures were solved by direct methods (SHELXS-97/SHELXS-2014) and refined by full-matrix least squares calculations on $F^{2}$ (SHELXL-2014) using the SHELX-TL program package. 


\section{Characterization of Synthesized Molecules}

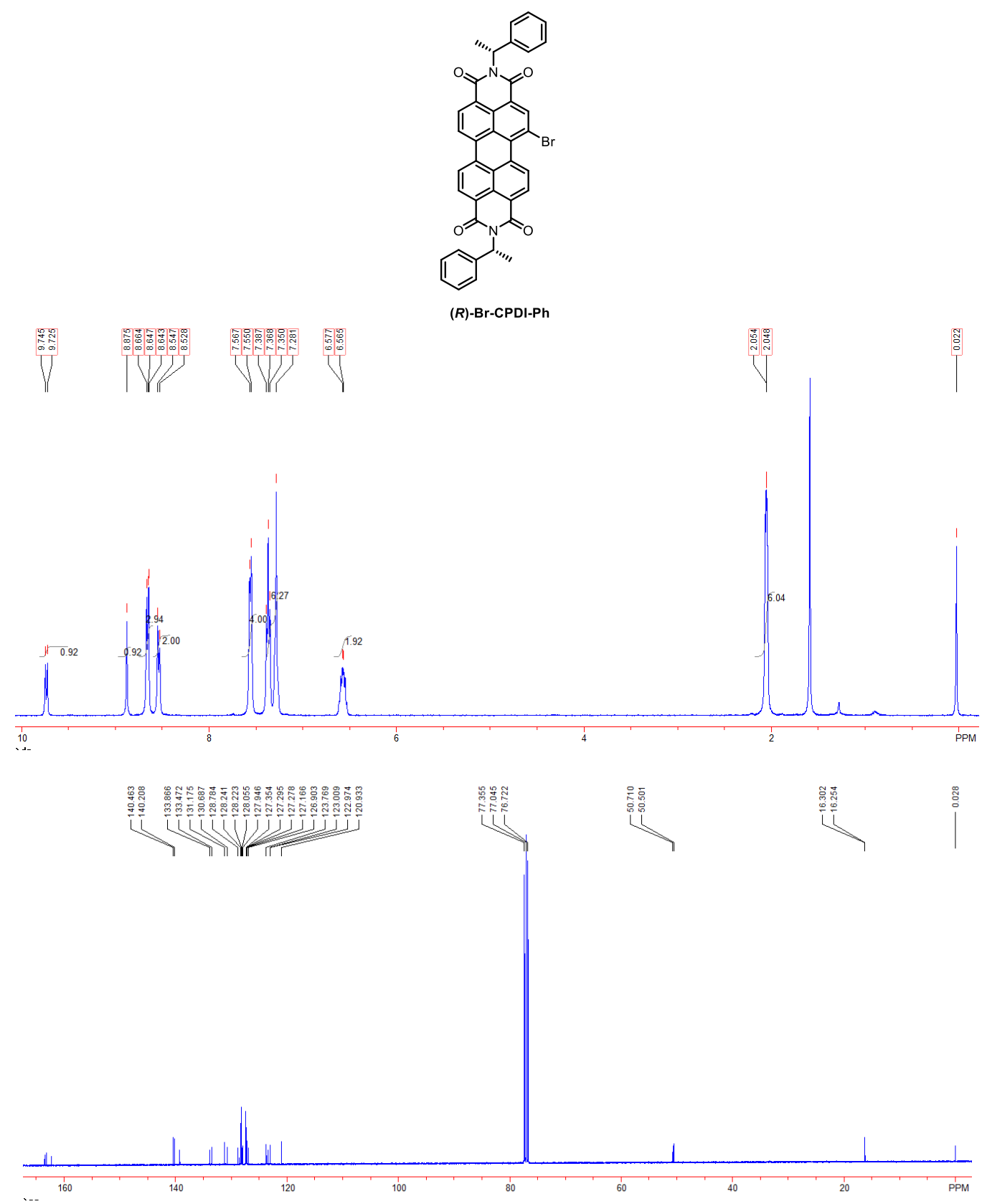

Figures S10. ${ }^{1} \mathrm{H}-\mathrm{NMR}$ spectra of $(R)$-Br-CPDI-Ph.

(R)-Br-CPDI-Ph: ${ }^{1} \mathrm{H}$ NMR (400 MHz, $\left.\mathrm{CDCl}_{3}\right): \delta 9.74(\mathrm{~d}, J=8.0 \mathrm{~Hz}, 1 \mathrm{H}), 8.88(\mathrm{~s}, 1 \mathrm{H}), 8.50-$ $8.70(\mathrm{~m}, 5 \mathrm{H}), 7.56(\mathrm{~d}, J=6.8 \mathrm{~Hz}, 4 \mathrm{H}), 7.24-7.42(\mathrm{~m}, 6 \mathrm{H}), 6.57$ (q, $J=6.8 \mathrm{~Hz}, 2 \mathrm{H}), 2.05$ (d, $J=7.2 \mathrm{~Hz}, 6 \mathrm{H}) \mathrm{ppm} .{ }^{13} \mathrm{C} \mathrm{NMR}\left(100 \mathrm{MHz}, \mathrm{CDCl}_{3}\right): \delta 163.5,163.2,163.1,162.3,140.5,140.2$, $139.2,133.9,133.5,133.5,133.5,131.2,130.7,128.8,128.6,128.2,128.2,128.1,127.9,127.4$, $127.3,127.3,127.2,126.9,123.8,123.8,123.6,123.3,123.0,123.0,120.9,50.7,50.5,16.3$, $16.3 \mathrm{ppm}$. HRMS $(\mathrm{m} / \mathrm{z}):\left[\mathrm{M}^{+}\right]$calcd for 676.0998 , found: 677.1072 . 


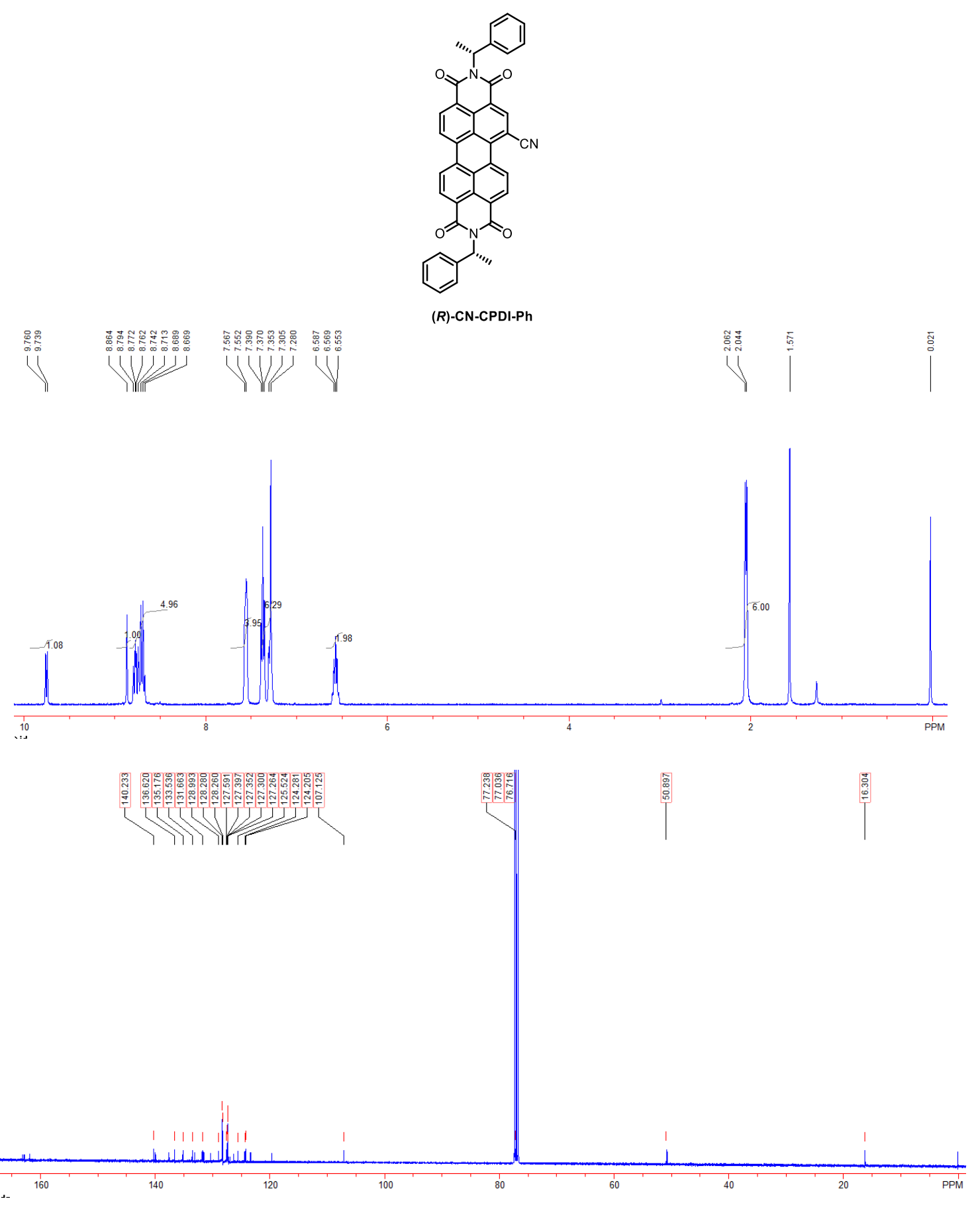

Figures S11. ${ }^{1} \mathrm{H}-\mathrm{NMR}$ spectra of $(R)-\mathrm{CN}-\mathrm{CPDI}-\mathrm{Ph}$.

(R)-CN-CPDI-Ph: ${ }^{1} \mathrm{H}$ NMR (400 MHz, $\left.\mathrm{CDCl}_{3}\right): \delta 9.75(\mathrm{~d}, J=8.4 \mathrm{~Hz}, 1 \mathrm{H}), 8.86(\mathrm{~s}, 1 \mathrm{H}), 8.65-$ $8.81(\mathrm{~m}, 5 \mathrm{H}), 7.52-7.60(\mathrm{~m}, 4 \mathrm{H}), 7.25-7.41(\mathrm{~m}, 6 \mathrm{H}), 6.56(\mathrm{q}, J=7.2 \mathrm{~Hz}, 2 \mathrm{H}), 2.05(\mathrm{~d}, J=$ $7.2 \mathrm{~Hz}, 6 \mathrm{H}) \mathrm{ppm} .{ }^{13} \mathrm{C} \mathrm{NMR}\left(100 \mathrm{MHz}, \mathrm{CDCl}_{3}\right): \delta 163.1,162.8,162.7,161.9,140.2,139.9$, 137.6, 136.6, 135.2, 133.5, 133.1, 131.9, 131.7, 131.5, 130.3, 129.0, 128.3, 128.3, 127.6, 127.4, $127.4,127.3,127.3,126.3,125.5,124.5,124.3,124.2,123.4,123.4,119.7,107.1,50.9,50.7$, 16.3, $16.2 \mathrm{ppm}$. HRMS $(\mathrm{m} / \mathrm{z}):\left[\mathrm{M}^{+}\right]$calcd for 623.1845 , found: 624.1920 . 


\section{Estimation of Optoelectrical Properties}

The field-effect mobility was calculated in the saturation regime using the following equation:

$$
I_{\mathrm{DS}}=\frac{W}{2 L} \quad C_{i} \mu\left(V_{\mathrm{GS}}-V_{\mathrm{T}}\right)^{2}
$$

where $I_{\mathrm{DS}}$ corresponds to the drain-source current, $W$ and $L$ are the channel width and length, respectively, $C_{\mathrm{i}}$ is the dielectric capacitance per unit area, $\mu$ is the field-effect mobility, $V_{\mathrm{GS}}$ is the gate-source voltage, and $V_{\mathrm{T}}$ is the threshold voltage.

In order to investigate optoelectronic properties for OPTs, photoresponsivity $(R)$ and photosensitivity $(P)$ were calculated from transfer characteristics coupled with light irradiation. The $R$ and $P$ values are typically defined by the following equations:

$$
\begin{gathered}
R=\frac{I_{\mathrm{ph}}}{P_{\mathrm{inc}}}=\frac{I_{\text {light }}-I_{\mathrm{dark}}}{P_{\text {inc }}} \\
P=\frac{I_{\text {light }}-I_{\text {dark }}}{I_{\text {dark }}}
\end{gathered}
$$

where $I_{\mathrm{ph}}$ is the photocurrent, $P_{\text {inc }}$ the incident illumination power on the channel of the device, $I_{\text {light }}$ the drain current under illumination, and $I_{\text {dark }}$ the drain current in the dark, respectively. In addition, the external quantum efficiency (EQE) ( $\eta$ ) of OPTs was calculated which can be defined as the ratio of number of photogenerated carriers that practically enhances the drain current to the number of photons incident onto the OPT channel area, using the following equation (S4):

$$
\eta=\frac{\left(I_{\text {light }}-I_{\text {dark }}\right) h c}{e P_{\text {int }} A \lambda_{\text {peak }}}
$$

where $h$ is the plank constant, $c$ the speed of light, $e$ the fundamental unit of charge, $P$ int the incident light intensity (i.e., the incident optical power density), $A$ the area of the transistor channel, and $\lambda_{\text {peak }}$ the peak wavelength of the incident light, respectively.

Detectivity usually describes the smallest detectable signal, which allows comparisons of photodetector devices with different configurations and areas. The specific detectivity can be thought of as the the signal to noise ratio generated by a photodetector with an active area $(A)$ of $1 \mathrm{~cm}^{2}$ at $1 \mathrm{~W}$ of incident power when the electrical bandwidth $(\Delta f)$ is $1 \mathrm{~Hz}$. $D^{*}$ was evaluated within this study using the following Equations (S5) and (S6):

$$
\begin{gathered}
D^{*}=\frac{\sqrt{A}}{N E P} \\
N E P=\frac{\sqrt{\overline{I_{n}^{2}}}}{R \sqrt{\Delta f}}
\end{gathered}
$$


In these equations, $A$ is the photodetector active area, NEP the noise equivalent power, and $\overline{I_{n}^{2}}$ the measured noise current. If the major limit to detectivity is shot noise from the drain current under dark conditions, $D^{*}$ can be simplified as:

$$
D^{*}=\frac{R}{\sqrt{\left(2 e \cdot I_{\text {dark }} / A\right)}}
$$

The rise time was extracted from the time required for the current to rise to $90 \%$ of the peak value after illumination, whereas the decay time was extracted from the time required for the current to be decayed to $10 \%$ of the maximum value after the cut off of illumination. 


\section{X-ray Crystallography}

\section{X-ray Crystallographic Data for $(R)-C N-C P D I-P h$ Single Crystal}

$\mathrm{C}_{41} \mathrm{H}_{25} \mathrm{~N}_{3} \mathrm{O}_{4}(M=623.64 \mathrm{~g} / \mathrm{mol})$ : monoclinic, space group $P 2_{1}$ (no. 4), $a=7.8360(16) \AA, b=$ 21.112(4) $\AA, c=18.169(4) \AA, \beta=101.14(3)^{\circ}, V=2949.1(11) \AA^{3}, Z=4, T=100(2) \mathrm{K}$, $\mu($ synchrotron $)=0.054 \mathrm{~mm}^{-1}$, Dcalc $=1.405 \mathrm{~g} / \mathrm{cm}^{3}, 16784$ reflections measured $\left(2.944^{\circ} \leq 2 \theta\right.$ $\left.\leq 59.886^{\circ}\right), 16771$ unique $\left(R_{\text {int }}=0.066, R_{\text {sigma }}=0.0530\right)$ which were used in all calculations. The final $R_{1}$ was $0.0982(\mathrm{I}>2 \sigma(\mathrm{I}))$ and $w R_{2}$ was 0.3001 (all data). Flack parameter: $-0.1(6)$; the enantiomer has been assigned by reference to an unchanging chiral center in the synthetic procedure. CCDC: 1889908 .

\section{X-ray Crystallographic Data for $(R)-2 F-C P D I-P h$ Single Crystal}

$\mathrm{C}_{40.5} \mathrm{H}_{25} \mathrm{ClF}_{2} \mathrm{~N}_{2} \mathrm{O}_{4}(M=677.07 \mathrm{~g} / \mathrm{mol})$ : triclinic, space group $P 1$ (no. 1), $a=8.3170(17) \AA,, b=$ 12.218(2) $\AA, c=\quad 15.239(3) \AA, \alpha=\quad 77.72(3)^{\circ}, \beta=\quad 87.35(3)^{\circ}, \gamma=86.42(3)^{\circ}, V=$ 1509.3(6) $\AA^{3}, Z=2, T=100(2) \mathrm{K}, \mu$ (synchrotron) $=0.142 \mathrm{~mm}^{-1}$, Dcalc $=1.490 \mathrm{~g} / \mathrm{cm}^{3}, 27301$ reflections measured $\left(3.364^{\circ} \leq 2 \theta \leq 57.298^{\circ}\right), 13531$ unique $\left(R_{\text {int }}=0.045, R_{\text {sigma }}=0.0646\right)$ which were used in all calculations. The final $R_{1}$ was $0.0709(\mathrm{I}>2 \sigma(\mathrm{I}))$ and $w R_{2}$ was 0.2113 (all data). Flack parameter: 0.14(4); The enantiomer has been assigned by reference to an unchanging chiral center in the synthetic procedure and anomalous dispersion of single crystal diffraction. CCDC: 1889911

\section{X-ray Crystallographic Data for $(R)-2 B r-C P D I-P h$ Single Crystal}

$\mathrm{C}_{40.5} \mathrm{H}_{24.75} \mathrm{Br}_{2} \mathrm{Cl}_{0.75} \mathrm{~N}_{2} \mathrm{O}_{4}(M=789.78 \mathrm{~g} / \mathrm{mol})$ : monoclinic, space group $P 2{ }_{1}($ no. 4$), a=$ 8.1830(16) $\AA, b=22.095(4) \AA, c=17.827(4) \AA, \beta=102.33(3)^{\circ}, V=3148.8(11) \AA^{3}, Z=$ $4, T=100(2) \mathrm{K}, \mu($ synchrotron $)=2.525 \mathrm{~mm}^{-1}$, Dcalc $=1.666 \mathrm{~g} / \mathrm{cm}^{3}, 29705$ reflections measured $\left(2.932^{\circ} \leq 2 \theta \leq 59.748^{\circ}\right), 17889$ unique $\left(R_{\text {int }}=0.0920, R_{\text {sigma }}=0.0881\right)$ which were used in all calculations. The final $R_{1}$ was 0.0595 (I $\left.>2 \sigma(\mathrm{I})\right)$ and $w R_{2}$ was 0.1722 (all data). Flack parameter: 0.013(4); the enantiomer has been assigned by reference to an unchanging chiral center in the synthetic procedure and anomalous dispersion of single crystal diffraction. CCDC: 1889912 